\title{
In vitro culture and production of syringin and rutin in Saussurea involucrata (Kar. et Kir.) - an endangered medicinal plant
}

\author{
Chao-Lin Kuo ${ }^{1}$, Dinesh-Chandra Agrawal ${ }^{2}$, Hung-Chi Chang ${ }^{2,3}$, Ya-Ting Chiu², Chu-Peng Huang ${ }^{2}$, Yi-Lin Chen ${ }^{4}$, \\ Shih-Hung Huang ${ }^{2}$ and Hsin-Sheng Tsay ${ }^{2,5^{*}}$
}

\begin{abstract}
Background: Saussurea involucrata (Kar. et Kir.) commonly known as 'snow lotus' or 'Xue Lian' is an important plant in the traditional Chinese system of medicine. The plant contains flavonoids such as syringin and rutin. These compounds have been reported to be anti-rheumatic, anti-inflammatory and dilate blood vessels, lower blood pressure, prevent cardiovascular diseases, enhance immunity, and act as anti-aging, anti-cancer, and anti-fatigue agents. The species has become endangered due to the excessive collection of $\mathrm{S}$. involucrata plants in the wild, slower plant growth and ecological destruction of natural habitats. There is a severe shortage of plant material, while the market demand is ever increasing. Hence, it is very important to apply tissue culture technique for plant propagation and production of the bioactive compounds of this species.
\end{abstract}

Results: Multiple shoot induction and proliferation in shoot base explants derived from in vitro raised seedlings of S. involucrata was achieved on 3/4 strength of Murashige and Skoog's (MS) basal medium (MSBM) supplemented with $1.0 \mathrm{mg} / \mathrm{L}^{-1} \mathrm{BA}$ and $1.5 \mathrm{mg} / \mathrm{L}^{-1}$ NAA. Rooting was induced in $100 \%$ shoots cultured on $1 / 2 \mathrm{X} \mathrm{MSBM}$ supplemented with $1.0 \mathrm{mg} / \mathrm{L}^{-1}$ IBA for one week and then transfer to auxin free medium. The plantlets could be acclimatized successfully by sachet technique and established in the greenhouse. Maximum callus induction and proliferation in leaf segments was achieved on 1/2X MSBM supplemented with $0.5 \mathrm{mg} / \mathrm{L}^{-1} \mathrm{BA}, 0.5 \mathrm{mg} / \mathrm{L}^{-1} \mathrm{NAA}$, $0.4 \%$ gelrite and on incubation at $20^{\circ} \mathrm{C}$. Container closures had an influence on the quality and quantity of callus and production of the active compounds. The HPLC analysis showed much higher syringin content in in vitro shoots and callus as compared to commercially available market crude drug.

Conclusion: The present study describes an in vitro culture protocol of Saussurea involucrata. The bioactive compounds, syringin and rutin could be produced through tissue culture technique without sacrificing the endangered Saussurea involucrata plants in the wild.

Keywords: In vitro culture; Medicinal plant; Rutin; Saussurea involucrata; Snow lotus; Syringin

\section{Background}

Saussurea involucrata (Kar. et Kir.) belonging to the family Asteraceae and commonly known as snow lotus or 'Xue Lian' in Chinese mainly grows in the high rocky mountains at 4000 to $4300 \mathrm{~m}$ in the Tianshan and A'er Tai areas in Xinjiang province of China (Fu 1992). The

\footnotetext{
* Correspondence: hstsay@cyut.edu.tw

2Department of Applied Chemistry, Chaoyang University of Technology,

Taichung, Taiwan

${ }^{5}$ Department of Agronomy, National Chung Hsing University, Taichung, Taiwan

Full list of author information is available at the end of the article
}

plant has been used in the traditional Chinese system of medicine for over 2000 years for the treatment of many diseases such as rheumatoid arthritis, cough and cold, stomachache, dysmenorrhea, altitude sickness, and has been found to have properties of anti-inflammatory, cardiotonic, abortifacient, anticancer, and antifatigue (Jia et al. 2005). Considering the importance of the species, recently several researchers carried out investigations with regard to the beneficial effects of $S$. involucrata. In pharmacological studies on S. involucrata, anti-inflammatory and anti-nociceptive properties have been reported (Yi et al. 
2010). In another investigation, petroleum ether extract of $S$. involucrata showed high anti-hypoxic activity effective in preventing acute mountain sickness (Ma et al. 2011). While studying to identify a potential agent for androgenindependent prostate cancer patients and to investigate its biological mechanism as an antineoplastic agent, Way et al. (2010) demonstrated that S. involucrata effectively inhibited EGFR signaling in human hormone-resistant prostate cancer PC-3 cells. A study on antimetastatic effects on SK-Hep1 human HCC cells found that S. involucrata could inhibit cell growth of metastatic cells in dose- and time-dependent manner demonstrating its potential as an anti-tumor agent (Byambaragchaa et al. 2013). S. involucrata produces several bioactive flavonoids that are derived from the phenylpropanoid pathway. A method validation study showed that the LC/MS technique was a powerful analytical tool for detecting trace amounts of the flavonoid compounds in extracts of $S$. involucrata (Xu et al. 2009). In a separate study, ethyl acetate extract from the aerial parts of S. involucrata led to the isolation of three new sesquiterpene lactones having significant anti-inflammatory and cytotoxic activities against A549 cells (Xiao et al. 2011). Pharmacological properties of syringin and rutin have been studied by several research groups. Syringin has been reported to possess anti-inflammatory and antinociceptive effects (Choi et al. 2004), hypoglycemic effect (Niu et al. 2008), antidepressant activity (Kurkin et al. 2006) and antitumor activity (Zhang et al. 2007). Rutin has several pharmacological properties including antioxidant (Katsube et al. 2006), anticarcinogenic, cytoprotective (Janbaz et al. 2002), antiplatelets (Sheu et al. 2004), and vasoprotective activities (La Casa et al. 2000). Moreover, rutin was found to be a neuroprotective agent, and can ameliorate ischemicreperfusion injury in the heart (Lebeau et al. 2001), brain (Gupta et al. 2003) and skeletal muscle (Neumayer et al. 2006).

Owing to slow plant growth, over exploitation of wild plants, and ecological destruction of the natural habits in recent years, there is a severe shortage of plant material of this species, while the market demand is ever increasing. The wild plant population has diminished to the extent that $S$. involucrata is now considered as an endangered species and has been listed as a national protected wild plant in China (Fu 1992). Due to these reasons, the isolation of active constituents from the wild plant is a serious constraint. Hence, there is a need to investigate alternative method for plant propagation and isolation of the active compounds. Plant tissue culture system can be an effective means to achieve these objectives. In the present study, Response Surface Methodology (RSM) was used to optimize a suitable medium for in vitro culture and callus induction in S. involucrata. HPLC analysis of in vitro cultures and market crude drug was carried out to estimate the active compounds syringin and rutin.

\section{Methods}

Plant material

Seeds of Saussurea involucrata were provided by Professor C.T. Wei of Department of Biotechnology, China Medical University, Taichung, Taiwan. Seeds were surface sterilized by submerging them into $70 \%$ ethyl alcohol for $30 \mathrm{~s}$ followed by $10 \%$ sodium hypochloride for $10 \mathrm{~min}$, and then rinsing them 3 times with sterile double distilled water. Disinfected seeds were inoculated in glass test tubes (measuring $120 \mathrm{~mm}$ long, $22 \mathrm{~mm}$ dia) containing Murashige and Skoog's (Murashige and Skoog 1962) salts and vitamins, hereinafter referred as MS basal medium (MSBM) supplemented with $0.9 \%$ agar and $3 \%$ sucrose. The $\mathrm{pH}$ of the medium was adjusted to $5.7 \pm 0.1$, prior addition of agar and before autoclaving for $15 \mathrm{~min}$ under $1.05 \mathrm{~kg} / \mathrm{cm}$ at $121{ }^{\circ} \mathrm{C}$. All the cultures were incubated at $25 \pm 2{ }^{\circ} \mathrm{C}$, under $14 / 10 \mathrm{~h}$ light and dark period and light intensity of $100 \mu \mathrm{E} / \mathrm{m}^{2}$ s provided by cool-white fluorescent lights. In vitro raised seedlings were used as source material for different experiments in the present study.

\section{Initiation and proliferation of shoots}

In an initial trial, five different basal media (salts and vitamins) viz. MS (Murashige and Skoog, 1962), WPM Woody plant medium (Lloyd and McCown 1981); B5 (Gamborg et al. 1968); N6 (Chu et al. 1975) and White (1963) without plant growth regulators (PGRs) were tested for initiation of shoots. Since, the best response was observed with MS basal medium, hence all further experiments were carried out with MS alone. Shoot base (Fig. 1a) excised from in vitro raised seedlings of S. involucrata was used as an explant for shoot initiation. Using RSM, a central composite factorial design was used for media optimization with 3 components viz. MS strength (1X, 3/4X, 1/2X and 1/4X), four concentrations of BA (1.0, 1.5, 2 and $2.5 \mathrm{mg} / \mathrm{L}^{-1}$ ) and NAA (0.5, 1.0 and $\left.1.5 \mathrm{mg} / \mathrm{L}^{-1}\right)$. All media were supplemented with $3 \% \mathrm{su}-$ crose and $\mathrm{pH}$ adjusted to $5.7 \pm 0.1$ prior to autoclaving. Glass test tube was used as a culture vessel closed with 2 layers of aluminum foil (2AF). After first subculture, explants with initiated shoots were transferred to $650 \mathrm{ml}$ capacity glass orchid flasks for further proliferation. Each culture flask containing $100 \mathrm{ml}$ medium was closed with 4 layers of dispense paper (DP4) and an additional layer of parafilm which was removed after 2 weeks. Both vitrified and normal shoots were cultured as separate sets. Cultures were incubated for total 7 weeks at $25 \pm 2{ }^{\circ} \mathrm{C}$, under $14 / 10 \mathrm{~h}$ light and dark period and light intensity of $100 \mu \mathrm{E} / \mathrm{m}^{2}$ s provided by cool-white fluorescent lights. 

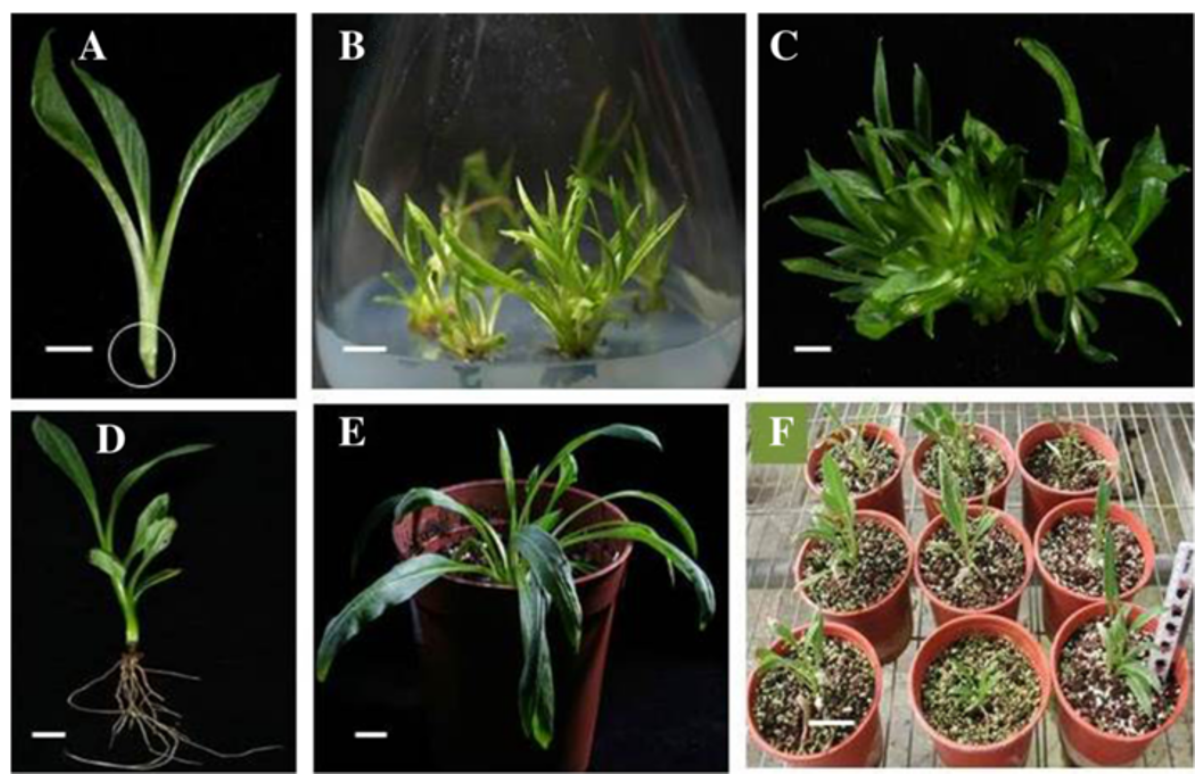

Fig. 1 In vitro culture of Saussurea involucrata Kar. et Kir. a: Shoot base explant (shown as in circle); b: Multiple shoots; c: Proliferation of shoots; $\mathbf{d}$ : Rooted shoot; $\mathbf{e}$ and $\mathbf{f}$ : Tissue culture plants in green house. Scale bar for $\mathbf{a}-\mathbf{d}=1 \mathrm{~cm} ; \mathbf{e} \& \mathbf{f}=2 \mathrm{~cm}$

\section{Rooting of in vitro shoots}

For induction of rooting in in vitro shoots, an initial trial was carried out with 3 auxins (IAA, IBA and NAA) individually, at a fixed concentration of $0.5 \mathrm{mgL}^{-1}$. Based on the higher response of rooting on MSBM containing IBA, further experiments were carried out with IBA alone. To optimize the rooting medium, 3 concentrations of IBA $\left(0.1,0.5\right.$ and $\left.1 \mathrm{mgL}^{-1}\right), 1 / 2$ strength of MSBM and two concentrations of sucrose (1.5 and $3 \%)$ were tested in a three factorial design. In vitro shoots were inoculated on medium with IBA for $1,2,3$, and 4 weeks and then transferred to medium without IBA for remaining 6, 5,4 and 3 weeks, respectively. All media were gelled with $0.9 \%$ agar. Orchid culture flasks were used as culture vessel and closed with two layers of non-permeable aluminum foil for two weeks, then replaced by 4 layers of dispense paper with an additional layer of parafilm which was removed after 2 weeks. All the cultures were incubated at $25 \pm 2{ }^{\circ} \mathrm{C}$, light and dark period of $14 / 10 \mathrm{~h}$ and light intensity of $100 \mu \mathrm{E} / \mathrm{m}^{2} \mathrm{~s}$ provided by cool-white fluorescent lights. Observations like the number of rooted shoots, number of roots and length of roots were recorded after 50 days of incubation.

\section{Transfer to soil}

Rooted shoots were removed from the culture vessel and agar adhering to the roots was removed by gently rinsing with running tap water. Then, these rooted shoots were transferred to plastic pots (15 cm dia. each) containing a mixture of peat soil: perlite: vermiculite (1:1:1) and kept in a greenhouse. Hardening of the plantlets was achieved by following the sachet technique described in our earlier report (Huang et al. 2014). The plants were irrigated once daily and survival was recorded after two months of transfer to pots.

\section{Induction and proliferation of callus}

Petiole, leaf and root parts of in vitro raised seedlings of S. involucrata were used as explants for callus induction. Explants were cultured on 1/2X MSBM supplemented with 2,4-D $(0.5,1.0 \mathrm{mgL}$ - 1), BA $(0.5,1.0,2.0 \mathrm{mgL}-1)$, and NAA $(0.5 \mathrm{mgL}-1), 3 \%$ sucrose and $0.4 \%$ gelrite. The $\mathrm{pH}$ of all media was adjusted to $5.7 \pm 0.1$. Petridishes (9 cm dia), each containing $25 \mathrm{ml}$ of medium were used for callus induction experiment. While, for proliferation experiment, glass test tubes, each containing $10 \mathrm{ml}$ medium were used. Callus (200 mg) was inoculated in each test tube and tubes were closed either with two layers of non-permeable aluminum foil (2AF) or with 3 dispense papers (3DP). Dispense papers had an additional layer of parafilm which was removed after 2 weeks. Observations on callus fresh weight under each treatment was recorded after 4 weeks of incubation. Experiments were carried out to optimize the callus proliferation using factors like temperature $\left(10,20,25{ }^{\circ} \mathrm{C}\right)$, and 5 chemical elicitors viz. salicylic acid, abscisic acid, phenylalanine, sodium acetate and jasmonic acid (at a fixed concentration $3 \mathrm{mgL}-1$ ) supplemented individually to $1 / 2 \mathrm{X}$ MSBM. All the cultures were incubated at $25 \pm$ $2{ }^{\circ} \mathrm{C}$ (except for temperature experiment), under dark. 


\section{HPLC analysis}

HPLC analysis was carried out to quantify syringin and rutin contents in in vitro shoots, callus and market crude drug. A reversed-phase symmetry-1 column $(250 \mathrm{~mm}$, 4.6X; $5 \mu \mathrm{m}$ particle size; Waters, USA) was used. The mobile phase was made up from solvent A (methanol) and solvent B (aqueous $0.3 \%$ formic acid in HPLC grade water). The solvent system used was a gradient of aqueous $0.3 \%$ formic acid and methanol. The gradient was as follows: 0 min, A; 3 min, A; 5 min, 15 \%, B; 15 min, $30 \%$, B; $20 \mathrm{~min}, 30 \%$, B. The flow rate was $1.0 \mathrm{ml} / \mathrm{min}$ and the injection volume was $10 \mu \mathrm{L}$. The chromatogram was monitored at $270 \mathrm{~nm}$ with a Waters DAD detector. Pure syringin and rutin samples used in the study as standards were procured from Formosa Kingstone Bioproducts International Corporation, Taiwan. Quantification was based on the peak area of the original sample injected. The recovery rate of extraction was evaluated by known quantities of syringin and rutin added to the biomass samples. The accuracy and reproducibility of syringin and rutin measurements were confirmed by analyzing different quantities of the samples.

\section{Statistical analysis}

Software SAS 9.1 was used for statistical analysis. Data were subjected to the least significant difference (LSD) tested at $5 \%$ probability level $(p \geq 0.05)$. Each treatment had minimum 30 replicates and all experiments were repeated minimum three times.

\section{Results and discussion}

\section{Initiation and proliferation of shoots}

Shoot initiation response in shoot base explants derived from in vitro raised seedlings of S. involucrata was very poor. Out of the five basal media tested, the maximum response in $49 \%$ explants with an average 0.85 shoot/explant was observed on 1/2X MSBM after 50 days of incubation. Non-responding shoots turned brown. In the first sub-culture, number of shoots per explant increased to 3.89 in $93.3 \%$ explants however shoots became vitrified (Fig. 1b). In the second subculture, a marked difference was observed between vitrified and normal (non-vitrified) explants and media composition with respect to the number of proliferating shoots. The maximum shoots (13 shoots/per explant) were observed on 3/4X MSBM supplemented with BA $\left(1.0 \mathrm{mg} / \mathrm{L}^{-1}\right)$ and NAA $\left(1.5 \mathrm{mg} / \mathrm{L}^{-1}\right)$ in case of normal (non-vitrified) explants, while vitrified explants resulted in 4.2 shoots/explant (Fig. 1c). The next best shoot proliferation (11.1 shoots/explant) was achieved on $1 / 4 \mathrm{X}$ MSBM supplemented with $2.0 \mathrm{mg} / \mathrm{L}^{-1} \mathrm{BA}$ and $0.5 \mathrm{mg} / \mathrm{L}^{-1} \mathrm{NAA}$ in case of non-vitrified explants. Since, media combinations in the 3 -factorial experiment are too many to tabulate, hence, here we have described only the best responses observed with regard to the number of shoots.

In an earlier study, a supplement of BA and NAA was reported to be the most effective growth regulator combination for induction of shoots in leaf explants of $S$. involucrata via organogenesis route (Guo et al. 2007). They initially recorded 5.2 shoots/explant on BA and NAA containing medium, but this shoot number could be increased to 9.3 by pre-treatment of leaf explants to $4{ }^{\circ} \mathrm{C}$ for 5 days. In the present study, a dramatic increase in shoot proliferation in second subculture could be due to culture of shoots in the larger vessels (orchid flasks having $650 \mathrm{ml}$ volume) compared to glass tubes ( $45 \mathrm{ml}$ volume) used in the first two cultures. Also, culture tube and orchid flask had differential medium content of $10 \mathrm{ml}$ and $100 \mathrm{ml}$, respectively. Thus, orchid flask had more volume and more medium content compared to the culture tube. Akin to our observation, a positive influence of larger culture vessel on shoot proliferation has been earlier been reported (McClelland and Smith 1990; Agrawal et al. 1997; Hazra et al. 2000). The positive influence of the larger vessel on increased shoot proliferation could be due to the availability of higher amounts of nutrients and a larger area for gaseous exchange.

\section{Rooting of in vitro shoots}

In an initial trial, out of three auxins (IAA, IBA and NAA) tested at a fixed concentration of $0.5 \mathrm{mg} / \mathrm{L}^{-1}$, the best rooting response was observed with IBA. Therefore, in order to further optimize the rooting medium, 3 concentrations of IBA $\left(0.1,0.5\right.$ and $\left.1.0 \mathrm{mgL}^{-1}\right)$ and two concentrations of sucrose (1.5 and $3 \%$ ) in the $1 / 2 \mathrm{X}$ MSBM were investigated. The maximum rooting response in $100 \%$ shoots, with an average of 6 roots/explant, and $6.5 \mathrm{~cm}$ root length was observed on 1/2X MSBM supplemented with $1.0 \mathrm{mg} / \mathrm{L}^{-1}$ IBA and $3 \%$ sucrose (Table 1 ). This treatment induced healthier roots and shoots compared to all other treatments (Fig. 1d). Medium with $0.1 \mathrm{mg} / \mathrm{L}^{-1} \mathrm{IBA}$, though induced rooting in $100 \%$ shoots, however average number of roots per shoot were limited to 3.57 and 2.71 with $1.5 \%$ and $3 \%$ sucrose in the medium, respectively (Table 1 ). Out of 4 IBA treatments for 1,2,3 and 4 weeks, the maximum rooting response was observed with IBA for 1 week and other three treatments did not show significant differences. Hence, Table 1 contains data pertaining to treatment of IBA for 1 week only. It was observed that shoots incubated in medium with auxin continuously for 50 days induced excessive callusing at the base and roots were shorter in length.

Efficient rooting of in vitro grown shoots is a prerequisite for the success of micropropagation. It is a common practice nowadays to employ lower salt concentrations in the culture medium for rooting of in vitro shoots. Higher salt levels in the medium have often been 
Table 1 The influence of IBA and sucrose concentrations on rooting of in vitro shoots in Saussurea involucrata Kar. et Kir

\begin{tabular}{|c|c|c|c|c|c|}
\hline $\mathrm{BA}\left(\mathrm{mg} / \mathrm{L}^{-1}\right)^{*}$ & Sucrose $\%$ & $\%$ of shoots rooted ${ }^{* *}$ & Av. no. of roots/explant** & Av. root length $(\mathrm{cm})^{* *}$ & Av. shoot height $(\mathrm{cm})^{* *}$ \\
\hline \multirow[t]{2}{*}{0.1} & 1.5 & $100^{\mathrm{a}}$ & $3.57^{\mathrm{abc}}$ & $5.8^{\mathrm{a}}$ & $4.50^{\mathrm{bc}}$ \\
\hline & 3.0 & $100^{\mathrm{a}}$ & $2.71^{a}$ & $5.6^{\mathrm{a}}$ & $3.57^{\mathrm{ab}}$ \\
\hline \multirow[t]{2}{*}{0.5} & 1.5 & $79^{c}$ & $3.00^{\mathrm{ab}}$ & $4.3^{\mathrm{ab}}$ & $4.87^{\mathrm{a}}$ \\
\hline & 3.0 & $93^{\mathrm{a}}$ & $3.92^{\mathrm{abc}}$ & $5.7^{\mathrm{ab}}$ & $4.14^{\mathrm{abc}}$ \\
\hline \multirow[t]{2}{*}{1.0} & 1.5 & $86^{\mathrm{ab}}$ & $3.33^{\mathrm{abc}}$ & $4.5^{\mathrm{a}}$ & $5.91^{\mathrm{abc}}$ \\
\hline & 3.0 & $100^{a}$ & $6.00^{\mathrm{abc}}$ & $6.5^{\mathrm{a}}$ & $5.07^{\mathrm{a}}$ \\
\hline
\end{tabular}

*1/2X MSBM: Murashige and Skoog (1962) basal medium (salts and vitamins), supplemented with $3 \%$ sucrose, $0.9 \%$ agar, pH $5.7 \pm 0.1$. Data were recorded after 7 weeks of culture. Shoots were cultured on IBA containing medim for 1 week and then transferred to PGR free MSBM containing $1.5 \%$ or $3 \%$ sucrose and $0.9 \%$ agar and further incubation for 6 weeks, respectively

${ }^{* *}$ Each treatment had thirty explants with three replicates. Means followed by the same letter $(a, b, c)$ of a column are not significantly different at $5 \%$ level by least significant difference (LSD) test

found inhibitory to root initiation (George et al. 2008). In a study on in vitro propagation of grapes, it was found that an appropriate salt concentration (1/2X or $1 /$ $4 \mathrm{X}$ MS) was more important than the sucrose level for induction of rooting in in vitro cuttings of grapevine (Harris and Stevenson 1979). The benefit of low salt medium for root initiation may be due to the need for a low nitrogen level, than for an increased osmotic potential (Harris and Stevenson, 1979). In an another study, it was demonstrated that microcuttings of several tree fruit rootstocks rooted best on MS salts, and the sucrose concentration in the medium was not critical, though its presence in the medium was essential (Dunstan 1981). Besides salts and sucrose, plant growth regulators (PGRs), especially, auxins are known to affect both root and shoot growth parameters and play an important role in root development. The success of auxin supply depends on its type, concentration and duration in the culture medium. Different plant species respond differently to auxins for the induction of rooting, hence, it is
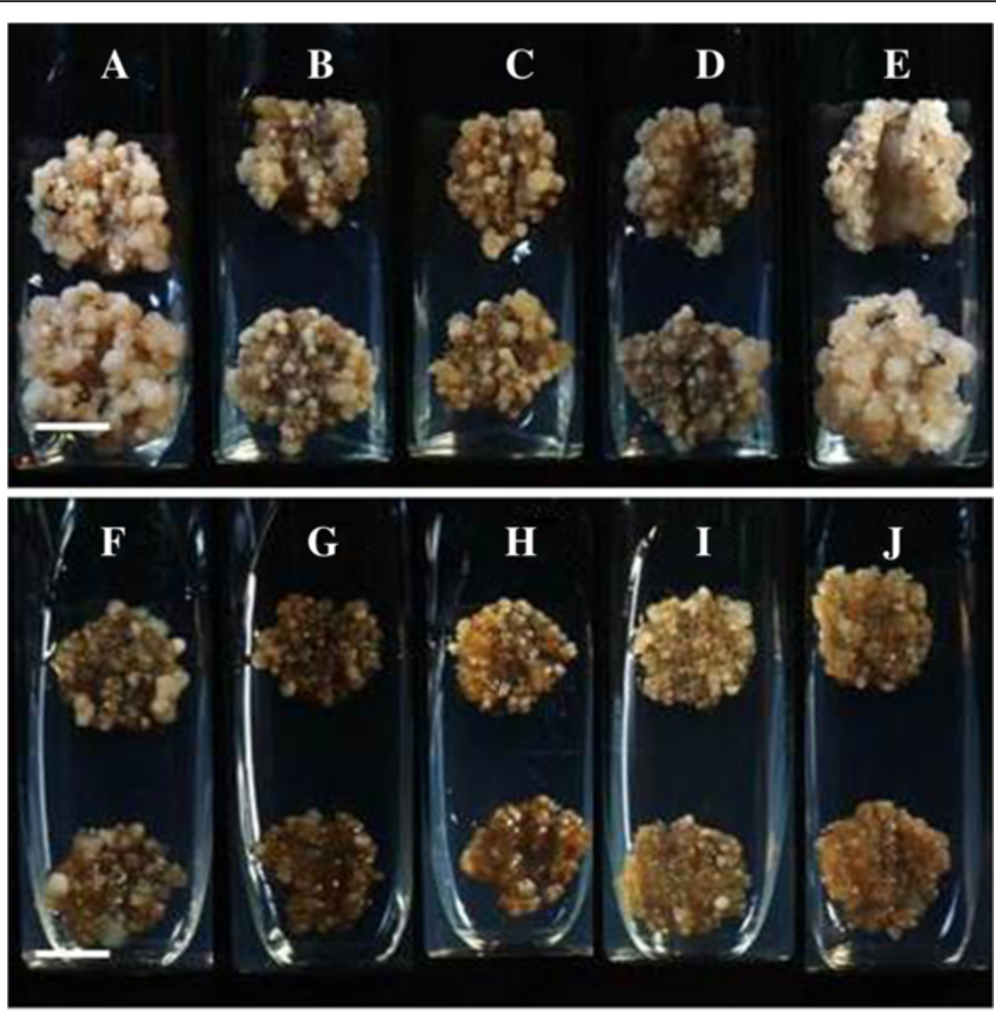

Fig. 2 Influence of PGRs and container closure on callus proliferation in Saussurea involucrata Kar. et Kir.: $\mathbf{a}$ and f: BA (1.0) + 2,4-D (1.0); b and g: $B A(1.0)+2,4-D(0.5) ; \mathbf{c}$ and $\mathbf{h}: B A(2.0)+2,4-D(0.5) ; \mathbf{d}$ and i: BA (0.5) + 2,4-D (0.5); e and j: BA (0.5) + NAA (0.5). PGR conc. - mg/L ${ }^{-1}$; Scale bar for $\mathbf{a}-\mathbf{j}=1 \mathrm{~cm}$. Culture medium: $1 / 2 \mathrm{X}$ MSBM, $3 \%$ sucrose, $04 \%$ gelrite. Culture tubes in treatments $\mathbf{a}$ to $\mathbf{e}$ were closed with 2 layers of aluminum foil $(2 \mathrm{AF})$, while in treatments $\mathbf{f}$ to $\mathbf{j}$ were closed with. 3 layers of dispense papers (3DP). Incubation at $20^{\circ} \mathrm{C}$ for 4 weeks 
important to optimize the type, concentration of an auxin and duration for which shoots need to be cultured in the auxin medium. In several cases, a pulse treatment with auxins for a short period has also been sufficient for root induction. While shoots of some species require longer exposure. In the present study, exposure of shoots to IBA containing medium for 1 week was sufficient. Continuous exposure of shoots to auxin medium for 7 weeks induced excessive callus, shorter and unhealthy shoots, an observation similar to our earlier report on G. davidii (Chueh et al. 2001). However, in contrast to our results, rooting in shoots of S. involucrata was achieved with a continuous exposure to IAA containing medium (Guo et al. 2007).

\section{Transfer of plantlets to soil and their survival in the greenhouse}

The sachet technique used in our previous report (Huang et al. 2014) was quite successful in hardening the tissue culture plantlets. Plantlets (100\%) could be hardened and established in the soil (Fig. 1e and f).

\section{Callus induction and proliferation}

Induction of callus in 3 explants viz. leaf, petiole and root of S. involucrata varied among the different media compositions. The highest response $(80 \%)$ was observed in leaf explants cultured on 1/2X MSBM supplemented with 0.5 or $1.0 \mathrm{mg} / \mathrm{L}^{-1} \mathrm{BA}, 0.5 \mathrm{mg} / \mathrm{L}^{-1} \mathrm{NAA}$ and $0.4 \%$ Gelrite. In the experiment with the incubation temperature, the maximum callus proliferation was recorded at $20{ }^{\circ} \mathrm{C}$. Sealing of culture vessels with aluminium foil or dispense papers had an influence on the quality and quantity of callus induced (Fig. 2). The maximum callus proliferation (1.036 g) was recorded on medium supplemented with $0.5 \mathrm{mg} / \mathrm{L}^{-1} \mathrm{BA}$ and $0.5 \mathrm{mg} / \mathrm{L}^{-1} \mathrm{NAA}$ and culture tubes closed with 3 layers of dispense papers (Table 2). Sealing of culture tubes with 2 layers of

Table 2 Influence of different elicitors on syringin and rutin content in callus of Saussurea involucrata Kar. et Kir

\begin{tabular}{llll}
\hline Elicitor & $\begin{array}{l}\text { Fresh weight } \\
(\mathrm{g})^{* *}\end{array}$ & $\begin{array}{l}\text { Syringin } \\
(\mathrm{mg} / \mathrm{g} \mathrm{dw})^{* * *}\end{array}$ & $\begin{array}{l}\text { Rutin } \\
(\mathrm{mg} / \mathrm{g} \mathrm{dw})\end{array}$ \\
\hline Control & $1.31^{\mathrm{b}}$ & $13.52^{\mathrm{a}}$ & 0.29 \\
Salicylic acid & $1.65^{\mathrm{a}}$ & $11.30^{\mathrm{bc}}$ & 0.29 \\
Abscisic acid & $1.74^{\mathrm{a}}$ & $8.75^{\mathrm{d}}$ & 0.31 \\
Phenylalanine & $1.73^{\mathrm{a}}$ & $10.73^{\mathrm{c}}$ & 0.37 \\
Sodium acetate & $1.58^{\mathrm{a}}$ & $12.85^{\mathrm{ab}}$ & 0.32 \\
Jasmonic acid & $1.59^{\mathrm{a}}$ & $14.79^{\mathrm{a}}$ & 0.32
\end{tabular}

*Basal medium:1/2X MSBM, BA $\left(0.5 \mathrm{mg} / \mathrm{L}^{-1}\right)$, NAA $0.5\left(\mathrm{mg} / \mathrm{L}^{-1}\right)$, elicitor $\left(3.0 \mathrm{mg} / \mathrm{L}^{-1}\right)$, sucrose $(3 \%)$, Gelrite $(0.4 \%)$ and $\mathrm{pH} 5.7 \pm 0.1$. Cultures were incubated at $20^{\circ} \mathrm{C}$. Data were recorded after 4 weeks of culture

**Callus $(0.2 \mathrm{~g})$ was taken as inoculum. Each treatment had 50 explants. Four random samples were analyzed in HPLC

${ }^{* * *} d w$ : Freeze dry weight; Means followed by the same letter $(a, b, c, d)$ were not significantly different at $5 \%$ level
Table 3 Influence of PGRs and container closure on callus proliferation in Saussurea involucrata Kar. et Kir

\begin{tabular}{llllll}
\hline \multicolumn{2}{l}{ PGR $\left(\mathrm{mg} / \mathrm{L}^{-1}\right)^{*}$} & & & \multicolumn{2}{l}{ Callus $(\mathrm{g})$} \\
\cline { 1 - 2 } \cline { 5 - 6 } $2,4-\mathrm{D}$ & BA & NAA & & 2 Aluminum foils** & 3 Dispense papers \\
\hline 0 & 0.5 & 0.5 & & $0.57^{\mathrm{b}}$ & $1.04^{\mathrm{a}}$ \\
0.5 & 0.5 & 0 & & $0.32^{\mathrm{e}}$ & $0.64^{\mathrm{bc}}$ \\
1.0 & 1.0 & 0 & & $0.46^{\mathrm{c}}$ & $0.74^{\mathrm{b}}$ \\
0.5 & 1.0 & 0 & & $0.44^{\mathrm{dc}}$ & $0.63^{\mathrm{bc}}$ \\
0.5 & 2.0 & 0 & & $0.38^{\mathrm{de}}$ & $0.52^{\mathrm{c}}$
\end{tabular}

*Basal medium: 1/2X MSBM, 3 \% sucrose, $0.4 \%$ Gelrite and pH $5.7 \pm 0.1$. Data were recorded after 4 weeks of culture

Each treatment had 30 explants in three replicates. Cultures were incubated at $20^{\circ} \mathrm{C}$. Callus $(0.2 \mathrm{~g})$ was taken as the initial inoculum

**Means followed by the same letter $(\mathrm{a}, \mathrm{b}, \mathrm{c}, \mathrm{d}, \mathrm{e})$ in a column were not significantly different at the \% level by LSD test

aluminum foil resulted in callii compact in texture and darker in color. While, in case of sealing of culture tubes with 3 layers of dispense papers, the callii were friable and fairer. Overall, the quality and quantity of callus proliferated in culture tubes sealed with 3 layers of dispense papers were superior and higher under all treatments compared to culture tubes sealed with 2 layers of aluminum foil (Table 3; Fig. 2). Inclusion of chemical elicitors had a mixed influence on the fresh weight of callus and syringin content (Table 2) All the five elicitors marginally enhanced the callus fresh weight, however, had a negetive influence on syringin content with an exception of jasmonic acid, which mariginally enhanced syringin content in callus $(14.788 \mathrm{mg} / \mathrm{g} \mathrm{dw})$ compared to control treatment $(13.524 \mathrm{mg} / \mathrm{g} \mathrm{dw})$. We did not observe any significant effect of any of the five elicitors on rutin content in callus which remained more or less same in all the treatments (Table 2).

The physical and chemical micro-environments of culture containers can influence growth rate and other physiological and morphological characteristics of plants developed under in vitro conditions (Walker et al. 1988). It has been reported that the type of closure affects gaseous exchange, availability of water, micronutrients, and balance of hormones in the culture container (Kataeva et al. 1991; Lai et al. 2005; Chen et al. 2006a; Tsay et al. 2006). The head space of culture vessels with low ventilation, accumulates various gaseous compounds like ethylene and carbon dioxide (Zobayed et al. 2001; Lai

Table 4 HPLC analysis: Syringin and rutin conents in different materials of Saussurea involucrata Kar. et Kir

\begin{tabular}{lll}
\hline Plant material & Syringin $(\mathrm{mg} / \mathrm{g} \mathrm{dw})^{*}$ & Rutin $(\mathrm{mg} / \mathrm{g} \mathrm{dw})^{*}$ \\
\hline Tissue culture shoots & 8.37 & 0.34 \\
Callus & 13.52 & 0.29 \\
Market crude drug & 0.95 & 0.24 \\
\hline
\end{tabular}

${ }^{*}$ dw: Freeze dry weight 
et al. 2005). These undesirable compounds can alter biochemical responses and leaf development of in vitro cultured plants (Pierik et al. 2007) and also affect enzymes involved in oxidative activities (Synková and Pospíšilová 2002). Some closures cause restriction of gaseous exchange between the container atmosphere and the outside environment (Buddendorf-Joosten and Woltering 1994), which can result in poor aeration and hyperhydric condition of cultures. Also, Different species show different requirement with respect to container closures. Hence, it is important to optimize a closure type in a micropropagation protocol of a particular plant species. In our laboratory, aluminum foil and dispense paper have been used successfully to improve ventilation for cultures of Scrophularia (Chen et al. 2006a), and Bupleurum (Chen et al. 2006b). It was observed that aluminum foil, a less air permeable material for first 4 weeks, followed by more air permeable dispense papers for the next 4 weeks was an adequate ventilation treatment for optimum root/shoot growth and subsequent survival of G. scabra plantlets (Huang et al. 2014). In the present study also a combination of foil and dispense paper was found to be a favorable combination for callus proliferation in S. involucrata. Similar to our results, a selective influence of chemical elicitors on the enhancement of secondary plant metabolites in callus has been reported earlier (Bulgakov et al. 2002). It was found that salicylic acid and methyl jasmonate had a positive influence on anthraquinone accumulation in both transgenic and non-transgenic calluses of Rubia cordifolia but ethephon did not (Bulgakov et al. 2002).

\section{HPLC analysis}

HPLC analysis of in vitro shoots, callus and market crude drug revealed marked differences in syringin content in these materials (Table 4). The highest syringin content $(13.52 \mathrm{mg} / \mathrm{g} \mathrm{dw})$ was observed in callus followed by in vitro shoots $(8.57 \mathrm{mg} / \mathrm{g} \mathrm{dw})$ compared to market crude drug $(0.95 \mathrm{mg} / \mathrm{g} \mathrm{dw})$. There was a marginal difference in rutin content in all the three materials. However, the positive outcome of the present study is that production of both syringin and rutin was achieved in an in vitro culture system.

\section{Conclusions}

An in vitro culture protocol for S. involucrata has been developed using Response Surface Methodology (RSM). Callus induction and proliferation could be achieved by in vitro leaf culture method. HPLC analysis results showed that syringin content was much higher both in callus and in vitro shoots compared to crude drug available in the market. Between the in vitro shoots and callus, the latter showed a higher syringin accumulation and could be a method of choice for the production of syringin and rutin. The present study demonstrates the usefulness of a tissue culture system with regard to production of the active compounds (syringin and rutin) round the year without the destruction of wild S. involucrata plants which are already under endangered category.

\section{Abbreviations}

AF: Aluminum foil; BA: 6-Benzylaminopurine; DP: Dispense paper:

HPLC: High- performance liquid chromatography; IAA: Indole-3-acetic acid; IBA: Indole-3-butyric acid; MS: Murashige and Skoog; MSBM: Muruashige \& Skoog's basal medium (salts and vitamins); NAA: 1-Naphthalene acetic acid; PGR: Plant growth regulator; RSM: Response surface methodology; WPM: Woody plant medium.

\section{Competing interests}

The authors declare that they have no competing interests.

\section{Authors' contributions}

YTC and CPH carried out the experimental work under the guidance/ supervision of CLK, HCC, YLC, SHH and HST. DCA wrote the manuscript. All authors have read and approved the final manuscript.

\section{Acknowledgement}

A research grant (NSC 102-2313-B-324-001-MY3) from the Ministry of Science and Technology (MOST), Taiwan is gratefully acknowledged.

\section{Author details}

'Department of Chinese Pharmaceutical Sciences and Chinese Medicine Resources, China Medical University, Taichung, Taiwan. ${ }^{2}$ Department of Applied Chemistry, Chaoyang University of Technology, Taichung, Taiwan. ${ }^{3}$ Department of Golden-Ager Industry Management, Chaoyang University of Technology, Taichung, Taiwan. ${ }^{4}$ Department of Biotechnology and Animal Science, National Ilan University, Yilan City, Taiwan. ${ }^{5}$ Department of Agronomy, National Chung Hsing University, Taichung, Taiwan.

Received: 1 April 2015 Accepted: 6 May 2015

Published online: 21 May 2015

\section{References}

Agrawal DC, Banerjee AK, Kolala RR, Dhage AB, Nalawade SM, Kulkarni AV, Hazra S, Krishnamurthy KV (1997) In vitro induction of multiple shoots and plant regeneration in cotton (Gossypium hirsutum L.). Plant Cell Rep 16:647-652. doi:10.1007/BF01275508

Buddendorf-Joosten JMC, Woltering EJ (1994) Components of the gaseous environment and their effects on plant growth and development in vitro. Plant Growth Regul 15:1-16. doi:10.1007/BF00024671

Bulgakov VP, Tchernoded GK, Mischenko NP, Khodakovskaya MV, Glazunov VP, Radchenko SV, Zvereva EV, Fedoreyev SA, Zhuravlev YN (2002) Effect of salicylic acid, methyl jasmonate, ethephon and cantharidin on anthraquinone production by Rubia cordifolia callus cultures transformed with the rolB and rolC genes. J Biotechnol 97:213-221. doi:10.1016/S0168-1656(02)00067-6

Byambaragchaa M, de la Cruz J, Yang SH, Hwang SG (2013) Anti-metastatic potential of ethanol extract of Saussurea involucrata against hepatic cancer in vitro. Asian Pac J Cancer Prev 14(9):5397-5402, http://dx.doi.org/10.7314/ APJCP.2013.14.9.5397

Chen UC, Hsia CN, Agrawal DC, Tsay HS (2006a) Influence of ventilation closures on plant growth parameters, acclimation and anatomy of leaf surface in Scrophularia yoshimurae Yamazaki - a medicinal plant native to Taiwan. Bot Stud 47:259-266

Chen UC, Hsia CN, Yeh MS, Agrawal DC, Tsay HS (2006b) In vitro micropropagation and ex vitro acclimation of Bupleurum kaoi - an endangered medicinal plant native to Taiwan. In Vitro Cell Dev Biol-PI 42:128-133. doi:10.1079/IVP2005744

Choi J, Shin KM, Park HJ, Jung HJ, Kim HJ, Lee YS, Rew JH, Lee KT (2004) Antiinflammatory and antinociceptive effects of sinapyl alcohol and its glucoside syringing. Planta Med 70:1027-1032. doi:10.1055/s-2004-832642

Chu CC, Wang CC, Sun CS, Hsu C, Yin KC (1975) Establishment of an efficient medium for anther culture of rice through comparative experiments on the nitrogen sources. Sci Sin 18:659-668

Chueh FS, Chen CC, Sagare AP, Tsay HS (2001) Quantitative determination of secoiridoid glucosides in in vitro propagated plants of Gentiana davidii var. 
formosana by high performance liquid chromatography. Planta Med 67:70-73. doi:10.1055/s-2001-10622

Dunstan DI (1981) Transplantation and post-transplantation of micropropagated tree-fruit rootstocks. Comb Proc Int Plant Prop Soc 31:39-44

Fu LG (1992) China plant red data book - rare and endangered plants, vol 1. Chinese Science Press, Beijing

Gamborg OL, Miller RA, Ojima K (1968) Nutrient requirements of suspension cultures of soybean root cells. Exp Cell Res 50:151-158. doi:10.1016/00144827(68)90403-5

George EF, Hall MA, De Klerk GJ (eds) (2008) Plant propagation by tissue culture Vol. 1. The background. Springer, The Netherlands

Gupta R, Singh M, Sharma A (2003) Neuroprotective effect of antioxidants on ischaemia and reperfusion-induced cerebral injury. Pharmacol Res 48:209-215. doi:10.1016/S1043-6618(03)00102-6

Guo B, Gao M, Liu CZ (2007) In vitro propagation of an endangered medicinal plant Saussurea involucrata Kar. et Kir. Plant Cell Rep 26:261-265. doi:10.1007/ s00299-006-0230-6

Harris RE, Stevenson JH (1979) Virus elimination and rapid propagation of grapes in vitro. Comb Proc Int Plant Prop Soc 29:95-108

Hazra S, Kulkarni AV, Nalawade SM, Banerjee AK, Agrawal DC, Krishnamurthy KV (2000) Influence of explants, genotypes and culture vessels on sprouting and proliferation of pre-existing meristems of cotton (Gossypium hirsutum L. and Gossypium arboreum L.). In Vitro Cell Dev Biol-PI 36:505-510. doi:10.1007/s11627-000-0090-7

Huang SH, Agrawal DC, Wu FS, Tsay HS (2014) In vitro propagation of Gentiana scabra Bunge - an important medicinal plant in the Chinese system of medicines. Bot Stud 55:56. doi:10.1186/s40529-014-0056-4

Janbaz KH, Saeed SA, Gilani AH (2002) Protective effect of rutin on paracetamoland $\mathrm{CCl}_{4}$-induced hepatotoxicity in rodents. Fitoterapia 73:557-563. doi:10.1016/S0367-326X(02)00217-4

Jia JM, Wu CF, Liu W, Yu H, Hao Y, Zheng JH, Ji YR (2005) Anti-inflammatory and analgesic activities of the tissue culture of Saussurea involucrata. Biol Pharma Bull 28(9):1612-1614. doi:org./10.1248/bpb.28.1612

Kataeva NV, Alexandrova IG, Butenko RG, Dragavtceva EV (1991) Effect of applied and internal hormones on vitrification and apical necrosis of different plants cultured in vitro. Plant Cell Tiss Org 14:31-40. doi:10.1007/BF00041283

Katsube T, Imawaka N, Kawano Y, Yamazaki Y, Shiwaku K, Yamane Y (2006) Antioxidant flavonol glycosides in mulberry (Morus alba L.) leaves isolated based on LDL antioxidant activity. Food Chem 97:25-31. doi:10.1016/ j.foodchem.2005.03.019

Kurkin VA, Dubishchev AV, Ezhkov VN, Titova IN, Avdeeva EV (2006) Antidepressant activity of some phytopharmaceuticals and phenylpropanoids. Pharm Chem J 40:614-619. doi:10.1007/s11094-006-0205-5

La Casa C, Villegas I, de la Lastra CA, Motilva V, Martin Calero MJ (2000) Evidence for protective and antioxidant properties of rutin, a natural flavone, against ethanol induced gastric lesions. J Ethnopharmacol 71:45-53. doi:10.1016/ S0378-8741(99)00174-9

Lai CC, Lin HM, Nalawade SM, Fang W, Tsay HS (2005) Hyperhydricity in shoot cultures of Scrophularia yoshimurae can be effectively reduced by ventilation of culture vessels. J Plant Physiol 162(3):355-61. doi:10.1016/j.jplph.2004. 07.015

Lebeau J, Neviere R, Cotelle N (2001) Beneficial effects of different flavonoids on functional recovery after ischemia and reperfusion in isolated rat heart. Bioorg Med Chem Lett 11:23-27. doi:10.1016/S0960-894X(00)00589-8

Lloyd G, McCown B (1981) Commercially feasible micropropagation of mountain laurel, Kalmia latifolia by shoot tip culture. Intl Plant Prop Soc Proc 30:421-427

Ma HP, Fan PC, Jing LL, Yao J, He XR, Yang Y, Chen KM, Jia ZP (2011) Antihypoxic activity at simulated high altitude was isolated in petroleum ether extract of Saussurea involucrata. J Ethnopharmacol 137(3):1510-5. doi:10.1016/j.jep.2011.08.037

McClelland MT, Smith MAL (1990) Vessel type, closure and explant orientation influence on in vitro performance of five woody species. HortSci 25:797-800

Murashige T, Skoog F (1962) A revised medium for rapid growth and bioassays with tobacco tissue cultures. Physiol Plant 15:473-497. doi:10.1111/J.13993054.1962.TB08052.X

Neumayer C, Fugl A, Nanobashvili J, Blumer R, Punz A, Gruber H, Polterauer P, Huk I (2006) Combined enzymatic and antioxidative treatment reduces ischemia-reperfusion injury in rabbit skeletal muscle. J Surg Res 133:150-158. doi:10.1016/j.jss.2005.12.005

Niu HS, Liu IM, Cheng JT, Lin CL, Hsu FL (2008) Hypoglycemic effect of syringin from Eleutherococcus senticosus in streptozotocin-induced diabetic rats. Planta Med 74:109-113. doi:10.1055/s-2008-1034275
Pierik R, Sasidharan R, Voesenek LCJ (2007) Growth control by ethylene: adjusting phenotypes to the environment. J Plant Growth Regul 26:188-200. doi:10.1007/s00344-006-0124-4

Sheu JR, Hsiao G, Chou PH, Shen MY, Chou DS (2004) Mechanisms involved in the antiplatelet activity of rutin, a glycoside of the flavonol quercetin, in human platelets. J Agric Food Chem 52:4414-4418. doi:10.1021/jf040059f

Synková H, Pospíšilová J (2002) In vitro precultivation of tobacco affects the response of antioxidative enzymes to ex vitro acclimation. J Plant Physiol 159:781-789. doi:10.1078/0176-1617-0511

Tsay HS, Lee CY, Agrawal DC, Basker S (2006) Influence of ventilation closure, gelling agent and explant type on shoot bud proliferation and hyperhydricity in Scrophularia yoshimurae - a medicinal plant. In Vitro Cell Dev Biol-PI 42:445-449. doi:10.1079/IVP2006791

Walker PN, Heuser CW, Heinemann PH (1988) Micropropagation: studies of gaseous environments. Acta Hort 230:145-151

Way TD, Lee JC, Kuo DH, Fan LL, Huang CH, Lin HY, Shieh PC, Kuo PT, Liao CF, Liu H, Kao JY (2010) Inhibition of epidermal growth factor receptor signaling by Saussurea involucrata, a rare traditional Chinese medicinal herb, in human hormone-resistant prostate cancer PC-3 cells. J Agric Food Chem 58(6):3356-65. doi:10.1021/jf903793p

White PR (1963) The cultivation of animal \& plant cells, 2nd edn. Ronald Press, New York

Xiao W, Li X, Li N, Bolati M, Wang X, Jia X, Zhao Y (2011) Sesquiterpene lactones from Saussurea involucrata. Fitoterapia 82(7):983-987. doi:10.1016/j.fitote. 2011.05.015

Xu YJ, Zhao DX, Fu CX, Cheng LQ, Wang NF, Han LJ, Ma FS (2009) Determination of flavonoid compounds from Saussurea involucrata by liquid chromatography electrospray ionisation mass spectrometry. Nat Prod Res 23:1689-98. doi:10.1080/14786410802187742

Yi T, Zhao ZZ, Yu ZL, Chen HB (2010) Comparison of the anti-inflammatory and anti-nociceptive effects of three medicinal plants known as "Snow Lotus" herb in traditional Uighur and Tibetan medicines. J Ethnopharmacol 128(2):405-11. doi:10.1016/j.jep.2010.01.037

Zhang W, Zhang WD, Zhang C, Liu RH, Li TZ, Fu P, Shan L (2007) Antitumor activities of extracts and compounds from the roots of Daphne tangutica Maxim. Phytother Res 21:1113-1115. doi:10.1002/ptr.2227

Zobayed SMA, Armstrong J, Armstrong W (2001) Leaf anatomy of in vitro tobacco and cauliflower plantlets as affected by different types of ventilation. Plant Sci 161:537-548. doi:10.1016/S0168-9452(01)00438-1

\section{Submit your manuscript to a SpringerOpen ${ }^{\odot}$ journal and benefit from:}

- Convenient online submission

$\checkmark$ Rigorous peer review

- Immediate publication on acceptance

- Open access: articles freely available online

- High visibility within the field

- Retaining the copyright to your article

Submit your next manuscript at $>$ springeropen.com 